\title{
Gender differences in career dissatisfaction among Pennsylvanian physicians
}

\author{
Brandon Vick* \\ Department of Economics, Indiana University of Pennsy/vania, United States
}

Received: January 10, 2017

DOI: $10.5430 /$ jha.v6n2p44

\author{
Accepted: February 19, 2017 \\ Online Published: March 3, 2017
}

\begin{abstract}
Objective: The physician workforce is quickly changing from one that was once male dominated to one that is more gender equal. The relationship between being female and physician career satisfaction is unclear despite a large body of research on the subject. I analyze the relationship between gender, career dissatisfaction, and plans to leave patient care. Female-male differences are calculated for various demographic, specialty, and practice setting subgroups of physicians; particular attention is paid to how various factors interact with gender.

Methods: Data comes from the 2012 Pennsylvania Health Workforce Survey of Physicians. I use multivariate, logistic regression to estimate associations between a number of covariates, including gender, and two outcomes: (1) career dissatisfaction, and (2) plans to leave patient care.

Results: Female physicians have $12 \%$ lower odds than males of reporting career dissatisfaction but no statistically significant difference in plans to leave patient care. Practicing in a hospital setting and in a rural county is associated with higher odds of dissatisfaction among male physicians but lower dissatisfaction among female physicians. Although female physicians own their practice at much lower rates, female owners have much lower odds of planning to leave patient care.

Conclusions: Factors associated with career dissatisfaction and plans to leave patient care affect male and female physicians differently, across race, rural practice, specialty, and practice ownership. Policy and research related to physician retention and quality of care should consider the interaction between gender and these factors in the future.
\end{abstract}

Key Words: Female physicians, Career satisfaction, Retention, Practice ownership

\section{INTRODUCTION}

The physician workforce is rapidly shifting from one that has been highly male-dominated in numbers to one that is gender-equal. In Pennsylvania, a state of nearly 13 million residents, only $21 \%$ of physicians ages 50 years and older are female, compared to $36 \%$ of those in their forties and $46 \%$ of those in their thirties. ${ }^{[1]}$ Given the growing demand for healthcare services in the United States, along with provider shortages in many areas and among many low-income popu- lations, ${ }^{[2]}$ physician career satisfaction and retention take on an important public health role. A recent review of studies found that physician career and job satisfaction was related to patient satisfaction, yielded better patient adherence to treatment, and had positive effects on the quality of overall care. ${ }^{[3]}$ Potential differences in physician satisfaction and attrition across gender, and how other factors affect female and male satisfaction differently, can inform policies and programs seeking to improve both the access to and quality of healthcare provision.

\footnotetext{
*Correspondence: Brandon Vick; Email: brandon.vick@iup.edu; Address: McElhaney Hall, Room 213, 441 North Walk, Indiana, PA 15705, United States. 
The relationship between physician satisfaction and gender is unclear despite a large body of research; the direction of the relationship differs across datasets, countries, and/or specialties. For instance, a study of general practitioners in Germany found that being female was associated with higher odds of satisfaction, ${ }^{[4]}$ while another group of recent studies found that female physicians had higher dissatisfaction rates and higher odds of work-life dissatisfaction than their male counterparts. ${ }^{[5,6]}$ Female physicians may have to contend with patients' gender perceptions that can hinder their ability to offer effective advice or care and potentially lead to work dissatisfaction. ${ }^{[7]}$ Despite these findings, a study of primary care pediatricians in Connecticut and a number of national studies, focused across a broader set of specialties, found similar levels of satisfaction between male and female doctors. ${ }^{[8-10]}$

The consequences of dissatisfaction can be upsetting to both patients and fellow practitioners when they lead one to leave her career in patient care. Controlling for dissatisfaction, a study on physician retirement found that being female is associated with earlier retirement. ${ }^{[11]}$ A study of hospital doctors found that work practices affected the out-of-work activities of female physicians more than male physicians and that females had higher odds of experiencing burnout. ${ }^{[12]}$ This result supported previous findings showing that female physicians were found to have higher odds of reporting burnout among primary and non-surgical care specialties. ${ }^{[13]}$ While it is true that the various regions studied above differ in their medical environments and their outcomes regarding career satisfaction, continued research in this field can help uncover various mechanisms leading to physician dissatisfaction.

The objective of this exploratory analysis is to analyze the relationship between being female, career dissatisfaction, and plans to leave patient care among Pennsylvania physicians. I estimate how various factors affect career dissatisfaction and plans to leave differently for female and male physicians. Finally, I test for male-female differences in these relationships across separate physician subgroups (i.e. demographic and specialty) and for differences in the primary source of dissatisfaction.

\section{MeThODS}

Data for the analysis comes from the 2012 Pennsylvania Health Workforce Survey of Physicians. The Pennsylvania State Board of Medicine is responsible for licensing physicians in the state, who are required to renew their license to practice every two years. ${ }^{[14]}$ The Pennsylvania Department of Health surveyed 46,715 physicians renewing their licenses in 2012 and supplied a modified data file to the author, withholding identifying information. Survey participation was

Published by Sciedu Press on a voluntary basis and the response rate was $90 \%$ of all physicians in the state.

In order to focus on career plans of the active Pennsylvania physician workforce, I placed a number of restrictions on the data related to age, active practice and missing observations, reducing the number of observations analyzed. First, I removed observations for physicians nearing retirement (56 years and over), since the factors related to retention of younger physicians are likely different from those related to retirement. This removed approximately $40 \%$ of all physicians. Second, since the focus is on the provision of patient care in Pennsylvania, I removed those who do not practice in Pennsylvania or who are not active in direct patient care, over $30 \%$ of the remaining physicians in the dataset. Third, I removed less than $1 \%$ of remaining observations due to missing data of a variable of interest used in the analysis. After incorporating these restrictions, this report analyzes the survey data on 17,444 physicians under 55 years old who were actively practicing patient care in Pennsylvania at the time of the survey.

Logistic regression is used to estimate the relationships between the two outcome areas (measures of dissatisfaction and plans to leave) and a number of explanatory variables. First, regressions are performed on a measure of career dissatisfaction. Physicians were asked how satisfied they have been with their overall careers and given options of answering very satisfied, satisfied, dissatisfied, or very dissatisfied. The dependent variable for dissatisfaction used in the logistic analyses equal one for responses of dissatisfied or very dissatisfied and zero otherwise. Second, logistic regressions are performed on a binary variable equal to 1 for those responding that they anticipate leaving patient care in the next six years and equal to 0 otherwise. Three regressions are performed on the dependent variables of dissatisfaction and plans to leave: the full sample of physicians, female physicians only, and male physicians only. In the full sample, a binary variable for female is included to test for gender differences in the odds of reporting dissatisfaction or plans to leave. In the female- and male-only samples, differences in the coefficient estimates for other covariates highlight how factors affect dissatisfaction and the plans to leave differently across gender.

To compliment the analysis of the full physician workforce, additional regressions were run to estimate whether being female is associated with career dissatisfaction and plans to leave among specific subgroups of physicians: by demographic, specialty, and practice setting characteristics. The goal is to identify whether gender differences vary across subgroups, among white vs. black physicians or rural vs. ur- 
ban ones, for instance. However, conducting statistical tests simultaneously across various subgroups increases the probability of type I error. To correct for multiple comparisons, the false discovery rate is restricted to $5 \%$, which is similar to Bonferroni correction in that it requires a $p$-value less than .05 for rejecting the null hypothesis. ${ }^{[15]}$ Additionally, to compare the gender coefficients across two subgroups, the Delta method is used to estimate $p$-values of a Wald test of equality.

A final analysis estimates gender differences across the primary sources of career dissatisfaction. Physicians were asked to name which characteristic is the greatest source of career dissatisfaction and, separately, of career satisfaction. Among the characteristics are the availability of leisure time, salary/income, and patient relationships. Binary variables for each characteristic were created and coded 1 if the physician named that characteristic as the greatest source of dissatisfaction and 0 otherwise. Logistic regressions are run on each source to estimate gender differences in the odds of reporting a particular source of dissatisfaction. The procedure was repeated for the question on sources of satisfaction.

Regression controls include the following: gender, race (white, black, Asian, and other), Hispanic ethnicity, age categories, primary care specialization, hospital practice, rural county practice, practicing in the western vs. eastern half of the state, the ratio of hours in non-practice activities (administration and research) to hours in patient care, total hours of work, and practice characteristics including ownership, employment of physician assistants and nurse practitioners, provision of safety net services, Medicaid/Medicare coverage, and delivery of babies as part of practice. A county is defined as rural in Pennsylvania if it has a population density lower than the statewide average. Primary care practitioners (PCPs) are defined by the American Academy of Family Physicians to include physicians whose primary specialty consists of one of the following: family practice physicians; internal medicine or general practice; and general pediatrics.

A number of robustness checks were performed and are available on request. Respondents answered questions on job experience, but this variable was withheld from the regression analysis due to high correlation with the age categories. Robustness checks found that experience controls had no substantive effect on coefficient estimates. As career dissatisfaction has been found to be associated with plans to leave, ${ }^{[11]}$ I performed additional robustness checks by including career dissatisfaction in all regressions on plans to leave patient care. Since the addition of dissatisfaction also had little effect on coefficient estimates for plans to leave, I present only results from the original model. The data analysis was performed using STATA version 12.1, a leading software package commonly used by social scientists performing statistical analyses, including multiple regression. ${ }^{[16]}$

Table 1. Descriptive characteristics of Pennsylvanian physicians under 55 years old

\begin{tabular}{|c|c|c|}
\hline Variable & $\begin{array}{l}\text { Male (\%) } \\
n=10,784\end{array}$ & $\begin{array}{l}\text { Female }(\%) \\
n=6,660\end{array}$ \\
\hline \multicolumn{3}{|l|}{ Specialty } \\
\hline - All Primary Care & 26.1 & 40.3 \\
\hline - General Pediatric \& Pediatric Specialist & 5.1 & 14.2 \\
\hline - Pediatric Specialist & 2.1 & 3.8 \\
\hline - Emergency & 6.2 & 4.8 \\
\hline - $\mathrm{OB} / \mathrm{GYN}$ & 2.5 & 7.8 \\
\hline - Surgery & 13.3 & 3.9 \\
\hline - Psychiatry & 4.5 & 5.5 \\
\hline - Anesthesiology & 6.7 & 4.2 \\
\hline - Radiology & 5.7 & 3.5 \\
\hline - Cardiology & 5.0 & 1.4 \\
\hline - Other Specialties & 28.0 & 24.8 \\
\hline \multicolumn{3}{|l|}{ Practice Setting } \\
\hline - Multi-Specialty Office & 7.7 & 7.7 \\
\hline - Single-Specialty Office & 28.1 & 34.2 \\
\hline - Solo Office & 5.7 & 4.7 \\
\hline - Inpatient Hospital & 35.2 & 26.1 \\
\hline - Outpatient Hospital & 12.8 & 16.6 \\
\hline \multicolumn{3}{|l|}{ Weekly Hours Ratios } \\
\hline - Administration / Patient Care & 22.3 & 19.9 \\
\hline - Research / Patient Care & 38.6 & 39.5 \\
\hline - Average Total Weekly Hours Worked & 56.9 & 49.3 \\
\hline \multicolumn{3}{|l|}{ Other Practice Characteristics } \\
\hline - Owns Practice & 28.3 & 14.6 \\
\hline - Set in Rural Pennsylvania & 17.9 & 12.8 \\
\hline - Employs Physician Assistants & 49.9 & 40.8 \\
\hline - Accepts Medicaid Patients & 88.0 & 87.4 \\
\hline - Accepts Medicare Patients & 94.2 & 87.0 \\
\hline - Currently Delivers Babies & 5.2 & 9.2 \\
\hline
\end{tabular}

Note. Source: Authors' calculations, Pennsylvania Health Workforce Surveys (2012). All gender differences are statistically significant at the .01 level

\section{RESULTS}

Female physicians make up $38 \%$ of the physician workforce under 55 years old in Pennsylvania (6,660 of 17,444 physicians). On average, female physicians are younger (45\% vs. $32 \%$ under 40 -years old) and more racially diverse (32\% vs. $25 \%$ non-white) than their male counterparts. The female physician workforce is distributed more heavily toward PCPs, pediatricians, and obstetricians and gynecologists $(\mathrm{OB} / \mathrm{GYNs})$, while having a lower fraction of surgeons than males, as shown in Table 1. Such crowding into different specialties by gender has been found in previous studies. ${ }^{[17]}$ A larger percentage of female physicians work in single-specialty offices and outpatient hospital settings than male physicians, while a larger proportion of male physicians practice in inpatient hospital settings. Additionally, a smaller percentage of female physicians locate in rural practices.

A number of other large male-female differences should be 
noted. First, male physicians work 8 more hours per week than females do on average $(p<.01)$. As shown in a recent study of work hours, surgery specialties tend to have higher average work hours than others. ${ }^{[18]}$ Second, while $28 \%$ of male physicians own their practice, only $15 \%$ of female physicians are owners $(p<.01)$. Third, likely related to differences in specialty and setting, a larger proportion of male physicians work in practices that employ physician assistants and accept Medicare patients, while a larger proportion of female physicians deliver babies as part of their practice $(p<.01$ for each difference).

Female versus male differences in the rates of career dissatisfaction and plans to leave patient care in the next six years are small but statistically significant, as shown in Table 2 . A higher percentage of males report being dissatisfied or very dissatisfied in the past year $(14 \%$ to $12 \%, p<.01)$ and overall $(10 \%$ to $8 \%, p<.01)$. The largest source of career dissatisfaction for both groups is the availability of leisure time, while the greatest source of satisfaction for both groups is patient relationships. A higher proportion of female physicians report plans to leave patient care in the next six years $(19 \%$ to $17 \%, p<.01)$, despite lower reports of dissatisfaction.

Table 2. Rates of career dissatisfaction and plans to leave among Pennsylvanian physicians under 55 years old

\begin{tabular}{lll}
\hline Variable & $\begin{array}{l}\text { Male (\%) } \\
\mathbf{n = 1 0 , 7 8 4}\end{array}$ & $\begin{array}{l}\text { Female (\%) } \\
\mathbf{n}=\mathbf{6 , 6 6 0}\end{array}$ \\
\hline Dissatisfied or Very Dissatisfied & \\
- With Career, Past Year & 13.8 & 11.7 \\
- With Career, Overall & 9.6 & 7.9 \\
Very Dissatisfied & & \\
- With Career, Past Year & 2.6 & 1.6 \\
- With Career, Overall & 1.5 & 0.8 \\
Greatest Source of Dissatisfaction & & \\
- Availability of Leisure Time & 28.9 & 31.2 \\
- Decision Making Autonomy & 8.2 & 6.4 \\
- Salary/Income & 9.7 & 10.7 \\
- Other Financial Reasons (incl.Insurance) & 16.0 & 12.8 \\
- Patient Relationships & 5.3 & 6.2 \\
- Practice Environment & 13.4 & 13.5 \\
- Other & 15.9 & 16.7 \\
Greatest Source of Satisfaction & & \\
- Decision Making Autonomy & 15.0 & 9.9 \\
- Salary/Income & 4.8 & 3.3 \\
- Intellectual Challenge & 24.8 & 21.7 \\
- Patient Relationships & 41.9 & 51.3 \\
- Practice Environment & 7.9 & 8.0 \\
Has Plans to Leave Patient Care in Next Six Years & \\
- Any Reason & 17.4 & 19.1 \\
- Stress/Demands & 2.3 & 2.3 \\
- Relocation & 6.0 & 7.7 \\
- Family Reasons & 2.6 & 3.9 \\
\hline Note. Source: Authors' calculations, Pennsylvania Health & Workforce Surveys \\
(2012). All gender differences are statistically significant at the .01 level \\
- & \\
\hline
\end{tabular}

Table 3 presents estimates from logistic regressions on career dissatisfaction and plans to leave patient care in Pennsylvania. The table reports odds ratios; those greater (less) than one suggest that a characteristic is related to higher (lower) odds of reporting dissatisfaction or plans to leave than its reference category. Despite similar response rates of career dissatisfaction shown in the previous section, female physicians have $12 \%$ lower odds of reporting dissatisfaction than their male counterparts, controlling for individual and practice characteristics (Column 1: OR $=0.88, p<.05$ ). Column 1 highlights a number of other factors associated with lower odds of dissatisfaction, including being non-white; working in a practice that employs physician assistants; working in a practice that accepts Medicaid patients; and having a higher research-to-patient care hours ratio. On the other hand, being a PCP, practicing medicine in a rural county, and higher weekly work hours are associated with higher dissatisfaction.

Estimating regression odds ratios of dissatisfaction for male and female physicians separately, I attempt to highlight differences in the factors associated with dissatisfaction, shown in Columns 2 and 3. For instance, being black is associated with lower odds of dissatisfaction among male physicians but not female physicians. While most of the covariates associate with dissatisfaction in a similar manner to estimates of the full sample (in Column 1), two other factors differ between male and female doctors. Practicing in a hospital setting is associated with higher odds of dissatisfaction for male physicians but lower odds for female physicians. Similarly, practicing in a rural county is associated with higher odds of dissatisfaction for male physicians but lower odds for female physicians, although the latter finding is not statistically significant. As shown in Columns 4-6, estimates suggest no statistically significant male-female differences in the odds of reporting plans to leave patient care.

In the next phase of the analysis, I performed logistic regressions on separate physician subgroups based on demographic characteristics, practice specialty, setting and ownership. Table 4 shows the estimated female-to-male odds ratios for each regression, suggesting that the relationship between gender and dissatisfaction varies across race, specialty, and setting. Among the subgroup of white physicians, females have $14 \%$ lower odds of dissatisfaction than males $(\mathrm{OR}=0.861$, $p<.05$ ). The opposite is true when analyzing only black physicians - female physicians have over twice the odds of reporting dissatisfaction than males $(\mathrm{OR}=2.237, p<.05)$. Results of Wald test of equality between the two subgroups suggest that the statistical relationship between gender and dissatisfaction are indeed different for black physicians compared to the relationship among white physicians $(p=.016$; this is also suggested by the non-overlapping confidence intervals of the estimates of both groups). 
Table 3. Characteristics associated with reporting career dissatisfaction and plans to leave patient care

\begin{tabular}{|c|c|c|c|c|c|c|}
\hline \multirow{4}{*}{ Independent Variables } & \multicolumn{6}{|c|}{ Dependent Variables } \\
\hline & \multicolumn{3}{|c|}{$\begin{array}{l}\text { Dissatisfied or Very Dissatisfied with } \\
\text { Medical Career (OR) }\end{array}$} & \multicolumn{3}{|c|}{$\begin{array}{l}\text { Has Plans to Leave Patient Care in } \\
\text { Next Six Years (OR) }\end{array}$} \\
\hline & (1) & (2) & (3) & (4) & (5) & (6) \\
\hline & All & Male & Female & All & Male & Female \\
\hline Female & $0.884^{*}$ & & & 0.954 & & \\
\hline Hispanic & 0.778 & 0.668 & 0.983 & $1.666^{* *}$ & $1.547^{* *}$ & $1.851^{* *}$ \\
\hline \multicolumn{7}{|l|}{ Race (Reference is White) } \\
\hline - Black & $0.641^{* *}$ & $0.382^{* *}$ & 0.910 & $1.999^{* *}$ & $1.636^{* *}$ & $2.408^{* *}$ \\
\hline - Asian & $0.522^{* *}$ & $0.510^{* *}$ & $0.545^{* *}$ & $1.525^{* *}$ & $1.508^{* *}$ & $1.559^{* *}$ \\
\hline - Other & 0.966 & 0.992 & 0.887 & $1.490^{* *}$ & $1.530^{* *}$ & $1.433^{*}$ \\
\hline Primary Care Practitioner (PCP) & $1.381^{* *}$ & $1.443^{* *}$ & $1.274^{*}$ & $0.853^{* *}$ & 0.934 & $0.767^{* *}$ \\
\hline Practices in Hospital Setting & 1.058 & $1.201^{*}$ & 0.813 & $1.644^{* *}$ & $1.571^{* *}$ & $1.751^{* *}$ \\
\hline Practice in Rural County & $1.175^{*}$ & $1.357^{* *}$ & 0.792 & $1.241^{* *}$ & $1.295^{* *}$ & 1.146 \\
\hline Owns Practice & 1.031 & 1.033 & 1.038 & $0.640^{* *}$ & $0.683^{* *}$ & $0.495^{* *}$ \\
\hline Employs Physician Assistants & $0.801^{* *}$ & $0.801^{* *}$ & $0.817^{*}$ & 1.055 & 1.050 & 1.077 \\
\hline Accepts Medicaid Patients & $0.744^{* *}$ & $0.682^{* *}$ & 0.886 & 0.896 & 0.918 & 0.866 \\
\hline Accepts Medicare Patients & $1.405^{* *}$ & 1.098 & $1.861^{* *}$ & $0.857^{*}$ & 0.807 & 0.889 \\
\hline Currently Delivers Babies & $1.738^{* *}$ & $1.997^{* *}$ & $1.418^{*}$ & $1.184^{*}$ & 1.172 & 1.192 \\
\hline Hrs. Ratio: Administration / Patient Care & 1.021 & 1.017 & 1.044 & $1.083^{* *}$ & $1.100^{* *}$ & 1.064 \\
\hline Hrs. Ratio: Research / Patient Care & $0.777^{* *}$ & $0.704^{* *}$ & $0.864^{*}$ & $1.030^{*}$ & 1.010 & $1.059^{*}$ \\
\hline Log: Average Total Weekly Hours Worked & $1.253^{* *}$ & $1.271^{*}$ & 1.233 & $1.159^{*}$ & $1.237^{*}$ & 1.052 \\
\hline Observations & 17,444 & 10,784 & 6,660 & 17,444 & 10,784 & 6,660 \\
\hline
\end{tabular}

Note. Source: Authors' calculations, Pennsylvania Health Workforce Surveys (2012). Table shows odds ratios estimated by logistic regression. Odds ratios greater than one suggest that a characteristic has higher odds of reporting dissatisfaction or plans to leave than its reference category. Full results (standard errors, confidence intervals, etc.) are available upon request; ${ }^{*}$ significant at 5\%; ${ }^{* *}$ significant at $1 \%$

Across different specialist groups in Table 4, estimated odds ratios consistently point toward lower odds of dissatisfaction for female physicians, with the sole exception of psychiatry. However, estimates are statistically significant only for PCPs and pediatricians, both of which associate being female with lower odds of dissatisfaction. Female physicians practicing in single-specialty offices and inpatient hospitals also have lower odds of reporting dissatisfaction while females in "other" settings have higher odds. Additionally, female physicians have $41 \%$ lower odds of dissatisfaction than males in rural practices but similar odds in urban practices. Wald tests comparing the rural vs. urban odds ratios suggest significant statistical differences in female-to-male odds ratios across the two areas $(p=.006$; also shown by non-overlapping confidence intervals).

A number of practice specialty and setting subgroups also show female-male differences in the odds of reporting plans to leave patient care. For instance, among PCPs, female physicians have $17 \%$ lower odds of reporting plans to leave than male. Among surgeons however, females have 41\% higher odds of having plans to leave than male surgeons, however this is not statistically significant at $5 \%$. Wald test estimates suggest that the lower female-to-male odds ratio for PCPs is a statistically significant difference from all non-PCP specialties $(p=.024)$. No statistically significant male-female differences are found in other specialties or across demographic groups.

Two findings related to practice setting should be highlighted. First, among physicians practicing in an outpatient hospital setting, females have $28 \%$ higher odds of planning to leave patient care. Second, females who own their practice have $32 \%$ lower odds of planning to leave patient care than male owners while non-owners have no gender difference.

To gain insight into the reasons for gender differences in career dissatisfaction, logistic regressions were run on the probability of giving various answers to questions related to the greatest source of career dissatisfaction and career satisfaction. Table 5 reports the female-to-male odds ratio estimates signifying gender differences in the reporting of each given source. Female physicians have $22 \%$ higher odds than males of reporting the lack of leisure time as the greatest source of dissatisfaction. They have lower odds than males of reporting decision-making autonomy and other financial reasons as the greatest source dissatisfaction. Regarding the greatest source of satisfaction, females have higher odds of 
reporting patient relationships than males but lower odds challenge as the greatest source.

of citing decision-making autonomy, salary, and intellectual

Table 4. Female-to-male odds ratios of reporting career dissatisfaction and plans to leave patient care

\begin{tabular}{|c|c|c|c|c|c|}
\hline \multirow[t]{2}{*}{ Subgroup of Physicians } & \multicolumn{2}{|c|}{$\begin{array}{c}\text { Dissatisfied or Very Dissatisfied with } \\
\text { Medical Career }\end{array}$} & \multicolumn{2}{|c|}{$\begin{array}{c}\text { Has Plans to Leave Patient Care in Next } \\
\text { Six Years }\end{array}$} & \multirow[t]{2}{*}{$n$} \\
\hline & Female-to-Male [OR] & $95 \% \mathrm{CI}$ & Female-to-Male [OR] & $95 \% \mathrm{CI}$ & \\
\hline All Physicians & $0.884^{*}$ & {$[0.785-0.994]$} & 0.954 & {$[0.873-1.041]$} & 17,444 \\
\hline \multicolumn{6}{|l|}{ Demographic } \\
\hline - Hispanic & 1.069 & {$[0.493-2.318]$} & 0.930 & {$[0.600-1.441]$} & 555 \\
\hline - White & $0.861^{*}$ & {$[0.754-0.984]$} & 0.964 & {$[0.863-1.076]$} & 12,594 \\
\hline - Black & $2.237^{*}$ & {$[1.064-4.703]$} & 1.258 & [0.833 - 1.899] & 631 \\
\hline - Asian & 0.889 & {$[0.645-1.226]$} & 0.911 & {$[0.766-1.082]$} & 3,587 \\
\hline - Other & 0.722 & {$[0.363-1.437]$} & 0.838 & {$[0.532-1.320]$} & 603 \\
\hline \multicolumn{6}{|l|}{ Specialty } \\
\hline - All PCPs & 0.841 & {$[0.697-1.015]$} & $0.825^{*}$ & {$[0.701-0.970]$} & 5,503 \\
\hline - All Pediatric & $0.575^{*}$ & {$[0.352-0.939]$} & 1.019 & [0.746 - 1.392] & 1,493 \\
\hline - Emergency & 0.904 & {$[0.580-1.407]$} & 1.134 & [0.811 - 1.586] & 991 \\
\hline - $\mathrm{OB} / \mathrm{GYN}$ & 0.920 & {$[0.581-1.456]$} & 0.924 & {$[0.608-1.404]$} & 787 \\
\hline - Surgery & 0.970 & {$[0.551-1.708]$} & 1.410 & {$[1.000-1.988]$} & 1,686 \\
\hline - Psychiatry & 1.584 & {$[0.891-2.816]$} & 1.033 & {$[0.692-1.542]$} & 847 \\
\hline - Anesthesiology & 0.686 & {$[0.375-1.255]$} & 0.906 & [0.602 - 1.362] & 957 \\
\hline - Radiology & 0.745 & {$[0.418-1.330]$} & 0.878 & {$[0.586-1.315]$} & 855 \\
\hline - Cardiology & 0.670 & {$[0.220-2.036]$} & 1.240 & {$[0.656-2.344]$} & 625 \\
\hline - Other Specialties & 0.918 & {$[0.704-1.196]$} & 0.865 & {$[0.729-1.026]$} & 4,670 \\
\hline \multicolumn{6}{|l|}{ Practice Setting } \\
\hline - Multi-Specialty Office & 1.323 & {$[0.831-2.108]$} & 1.075 & {$[0.728-1.586]$} & 1,300 \\
\hline - Single-Specialty Office & 0.840 & {$[0.685-1.029]$} & 0.871 & {$[0.716-1.061]$} & 5,308 \\
\hline - Solo Office & 0.815 & {$[0.534-1.243]$} & 0.713 & {$[0.443-1.146]$} & 928 \\
\hline - Inpatient Hospital & $0.744^{*}$ & [0.584-0.948] & 0.926 & [0.804 - 1.067] & 5,538 \\
\hline - Outpatient Hospital & 0.921 & {$[0.668-1.270]$} & $1.277^{*}$ & {$[1.028-1.586]$} & 2,490 \\
\hline Urban & 0.946 & {$[0.832-1.077]$} & 0.957 & {$[0.870-1.054]$} & 14,655 \\
\hline Rural & $0.590^{* *}$ & {$[0.432-0.805]$} & 0.904 & {$[0.720-1.134]$} & 2,789 \\
\hline \multicolumn{6}{|l|}{ Practice Ownership } \\
\hline - Owns Practice & 0.846 & [0.662 - 1.083] & $0.679^{* *}$ & {$[0.506-0.911]$} & 4,025 \\
\hline - Does not Own Practice & 0.892 & {$[0.779-1.022]$} & 0.975 & {$[0.888-1.070]$} & 13,419 \\
\hline
\end{tabular}

Note. Source: Authors' calculations, Pennsylvania Health Workforce Surveys (2012). Table shows odds ratios estimated by logistic regression. Odds ratios greater than one suggest that a characteristic has higher odds of reporting dissatisfaction or plans to leave than its reference category. Full results (standard errors, confidence intervals, etc.) are available upon request; ${ }^{*}$ significant at $5 \% ;{ }^{* *}$ significant at $1 \%$

\section{Discussion}

Approximately $9 \%$ of physicians under 55 years old are dissatisfied with their overall careers, and $18 \%$ have plans to leave patient care in Pennsylvania in the next six years. Regression estimates find that female physicians have lower odds of reporting dissatisfaction than males but have no statistically significant difference in the plans to leave patient care. Utilizing a large physician dataset and focusing on younger physicians, this paper is one of the few studies to focus on female-male differences across physician subgroups, by demographic, specialty, and practice setting, finding significant differences in a number of areas. ${ }^{[19]}$ For instance, being fe- male is associated with lower dissatisfaction among white physicians but higher dissatisfaction among black physicians. Female physicians have lower odds of dissatisfaction than male physicians in rural settings, but this difference is not found in urban ones. Female PCPs have lower odds of planning to leave patient care while female surgeons have higher odds. While other studies have found little career satisfaction differences across gender, the current focus on younger physicians may account for the different findings here.

This study supports previous research that attempted to isolate various reasons for differences in female vs. male physician career satisfaction. A recent study of Dutch physicians 
found that females were less satisfied than their male counterparts in terms of their own professional accomplishments, while younger female physicians were more satisfied with opportunities for career development. ${ }^{[20]}$ Similar to the results shown in Table 5, the Dutch study also found male physicians to be more satisfied with income than females. A systematic review of the subject found that women physicians generally had similar levels of career satisfaction compared to men but were more concerned with a lack of time for relationships with family, similar to the results found here. ${ }^{[19]}$ Another study found most women physicians to be generally satisfied with their careers, similar to results from Table 2. The strongest factor related to satisfaction among women physicians was work control and the youngest physicians were found to have less control. ${ }^{[21]}$ As most female physicians are younger than males in the current study, it is not surprising that they are also less likely to cite decision-making autonomy as a source of satisfaction in Table 5.

Table 5. Female-to-male odds ratios of sources of career dissatisfaction and career satisfaction

\begin{tabular}{lll}
\hline Dependent Variable & $\begin{array}{l}\text { Female-to-Male } \\
\text { [OR] }\end{array}$ & [CI] \\
\hline Greatest Source of Dissatisfaction & & \\
- Availability of Leisure Time & $1.216^{* *}$ & {$[1.131-1.309]$} \\
- Decision Making Autonomy & $0.771^{* *}$ & {$[0.676-0.879]$} \\
- Salary/Income & 0.973 & {$[0.872-1.086]$} \\
- Other Financial Reasons & $0.820^{* *}$ & {$[0.743-0.905]$} \\
- [incl. Insurance] & 0.900 & {$[0.781-1.038]$} \\
- Patient Relationships & 1.042 & {$[0.944-1.149]$} \\
- Practice Environment & 0.995 & {$[0.908-1.089]$} \\
- Other & & \\
Greatest Source of Satisfaction & $0.704^{* *}$ & {$[0.634-0.781]$} \\
- Decision Making Autonomy & $0.624^{* *}$ & {$[0.524-0.743]$} \\
- Salary/Income & $0.899^{*}$ & {$[0.828-0.976]$} \\
- Intellectual Challenge & $1.376^{* *}$ & {$[1.282-1.477]$} \\
- Patient Relationships & 0.952 & {$[0.842-1.077]$} \\
\hline - Practice Environment &
\end{tabular}

Source: Authors' calculations, Pennsylvania Health Workforce Surveys (2012). $\mathrm{n}=17,444$ for each regression. Table shows female-to-male odds ratios estimated by logistic regression. Odds ratios greater than one suggest that female physicians have higher odds of reporting dissatisfaction or plans to leave than males. Additional controls are not reported here but are available upon request; ${ }^{*}$ significant at $5 \% ;{ }^{* *}$ significant at $1 \%$

The precise mechanism leading to female vs. male differences in dissatisfaction and plans to leave is hard to identify and may require additional pieces of information. First, the Health Workforce Surveys used here do not ask questions about income. Previous studies suggest that income plays a role in dissatisfaction and plans to leave, although this may not be the primary driver. ${ }^{[22,23]}$ However, the results presented in Table 5 suggest little difference in dissatisfaction with income across gender. Second, the survey data do not capture information related to family, such as children and the presence of a second earner in the household. If having children is associated with career dissatisfaction or plans to leave, and if female physicians bear a disproportionate family burden compared to males, then the effects of family may be captured by the estimated female-to-male odds ratios and bias these estimates. Alternatively, disproportionate family burdens may lead more female physicians to stop actively practicing medicine, biasing our sample since we removed non-active physicians. However, male and female physicians were removed for not being active for family reasons at similar rates (approximately $2 \%$ of each group). Previous work suggests that family life is affected in similar ways across gender. For instance, a study of German gynecologists finds that at least $37 \%$ of both female and male physicians reported neglecting their children and families. ${ }^{[24]}$ Third, the survey instrument does not include questions related to the Affordable Care Act (ACA), which has had major impacts on job satisfaction across the health workforce. However, controls for Medicaid and Medicare acceptance may be capturing some effects of changes to the payment models that were being implemented at the time of the survey. Additionally, sources of dissatisfaction, such as the lack of autonomy or financial concerns, may be related to implementation of the ACA, However, specific conclusions about the effects of the ACA on physician satisfaction is beyond the scope of this paper. Despite limitations with the data, results of this exploratory analysis suggest a number of important avenues for further study.

\section{Conclusions}

Female-male differences in satisfaction and plans to leave may affect health care provision in a number of areas. Further research should investigate the mechanisms underlying the different female responses among white versus black physicians and rural versus urban physicians. The finding that females have higher odds of dissatisfaction among black physicians is troubling given that poverty rates in Pennsylvania are higher for racial minorities, which potentially face greater barriers to healthcare. ${ }^{[25]}$ Two results have implications for rural health policy. On the one hand, fewer female physicians locate rurally than male physicians (13\% of female vs. $18 \%$ of male physicians); on the other hand, among the group of rural physicians, females have $41 \%$ lower odds of dissatisfaction. The lack of female physicians and their relatively higher career satisfaction suggests that policies to increase the number of female doctors in rural areas should focus on recruitment, while seeking to understand and maintain high satisfaction.

Among physicians who own their medical practice, females have $32 \%$ lower odds of leaving patient care than male own- 
ers. However, a much lower proportion of female physicians own their practices compared to males (15\% to $28 \%$ ). More research should seek to disentangle whether the lower prevalence of female practice ownership is due to either (1) preferences to not own the practice or (2) constraints against owning the practice. While a recent nationally representative profile of physicians suggests that male doctors "favor" small practices, ${ }^{[26]}$ our estimates suggest that ownership has no relation to satisfaction; instead, owners have lower odds of leaving patient care earlier in their careers (compared to non-owners). The low prevalence of female ownership may be indicative of constraints to ownership rather than the preference not to own. Given that female practice owners have lower odds of leaving the practice, ownership incentives for female physicians may be a retention policy worth exploring further.

\section{FUNDING STATEMENT}

This work was supported by a grant from the Center for Rural Pennsylvania, a legislative agency of the Pennsylvania General Assembly.

\section{ACKNOWLEDGEMENTS}

Health workforce data were supplied by the Bureau of Health Planning, Pennsylvania Department of Health, Harrisburg, Pennsylvania. The Pennsylvania Department of Health specifically disclaims responsibility for any analyses, interpretations, or conclusions. I would like to thank Dr. Dave Yerger and Margaret Gagel for their generous comments and suggestions.

\section{CONFLicts of InTEREST Disclosure}

I have no associations that pose or appear to pose a conflict of interest in connection with this research.

\section{REFERENCES}

[1] Vick B, Gagel M, Yerger D. Assessing Career Dissatisfaction and Plans to Leave Patient Care Among the Rural Pennsylvania Health Workforce. Center for Rural Pennsylvania Report. 2015.

[2] U.S. Health Resources and Services Administration. Shortage Designation: Health Professional Shortage Areas \& Medically Underserved Areas/Populations [HRSA website]. 2015. Available from: http: //bhpr.hrsa.gov/shortage/. Accessed 20 Feb 2015.

[3] Scheepers RA, Boerebach BCM, Arah OA, et al. A Systematic Review of the Impact of Physicians' Occupational Well-Being on the Quality of Patient Care. Int J Behav Med. Mar 2015. PMid: 25733349. https://doi.org/10.1007/s12529-015-9473-3

[4] Goetz K, Musselmann B, Szecsenyi J, et al. The influence of workload and health behavior on job satisfaction of general practitioners. Fam Med. 2013; 45(2): 95-101. PMid: 23378076.

[5] Dyrbye LN, Varkey P, Boone SL, et al. Physician satisfaction and burnout at different career stages. Mayo Clin Proc. 2013; 88(12): 1358-367. PMid: 24290109. https://doi.org/10.1016/j.ma yocp. 2013.07.016

[6] Shanafelt TD, Boone S, Tan L, et al. Burnout and satisfaction with work-life balance among US physicians relative to the general US population. Arch Intern Med. 2012; 172(18): 1377-1385. PMid: 22911330. https://doi.org/10.1001/archinternmed. 2012 .3199

[7] Mast MS, Hall J, Cronauer C, et al. Perceived dominance in physicians: Are female physicians under scrutiny? Patient Educ Couns. 2011; 83(2): 174-179. PMid: 20673619. https ://doi.org/10.1 016/j.pec. 2010.06 .030

[8] Brazil K, Wakefield DB, Cloutier MM, et al. Organizational culture predicts job satisfaction and perceived clinical effectiveness in pediatric primary care practices. Health Care Manage Rev. 2010; 35(4): 365-71. PMid: 20844361. https://doi.org/10.1097/HMR. Ob 013 e3181edd957

[9] Keeton K, Fenner DE, Johnson TRB, et al. Predictors of physician career satisfaction, work-life balance, and burnout. Obstet Gynecol. 2007; 109(4): 949-55. PMid: 17400859. https ://doi.org/10.1 097/01.AOG.0000258299.45979.37
[10] Leigh JP, Tancredi DJ, Kravitz RL. Physician career satisfaction within specialties. BMC Health Serv Res. 2009; 9(1): 166. PMid: 19758454. https://doi .org/10.1186/1472-6963-9-166

[11] Landon BE, Reschovsky JD, Pham HH, et al. Leaving medicine: the consequences of physician dissatisfaction. Med Care. 2006; 44(3): 234-42. PMid: 16501394. https://doi.org/10.1097/01.mlr $.0000199848 .17133 .9 \mathrm{~b}$

[12] Walsh J. Gender, the Work-Life Interface and Wellbeing: A Study of Hospital Doctors. Gend Work Organ. 2013; 20(4): 439-453. https://doi.org/10.1111/j.1468-0432.2012.00593.x

[13] McMurray JE, Linzer M, Konrad TR, et al. The work lives of women physicians results from the physician work life study. The SGIM Career Satisfaction Study Group. J Gen Intern Med. 2000; 15(6): 372-80. PMid: 10886471.

[14] Pennsylvania Bureau of Health Planning (PABHP). 2012 Pulse of Pennsylvania's physician and physician assistant workforce. Pennsylvania Department of Health Technical Report. 2014; 5.

[15] Benjamini Y, Hochberg Y. Controlling the False Discovery Rate: a Practical and Powerful Approach to Multiple Testing. J Royal Stat Soc. Series B (Methodological). 2005; 57(1): 289-300.

[16] STATA Statistics/Data Analysis [computer program]. Version 12.1. StataCorp LP, College Station, Texas, USA.

[17] Lambert EM, Holmboe ES. The relationship between specialty choice and gender of U.S. medical students, 1990-2003. Acad Med. 2005; 80(9): 797-802. PMid: 16123456. https://doi.org/10.1097/ 00001888-200509000-00003

[18] Leigh JP, Tancredi D, Jerant A, et al. Annual work hours across physician specialties. Arch Inter Med. 2011; 171(13): 1211-1213. PMid: 21747020. https://doi.org/10.1001/archinternmed. 2011. 294

[19] Rizvi R, Raymer L, Kunik M, et al. Facets of career satisfaction for women physicians in the United States: a systematic review. Women \& health. 2012; 52(4): 403-21. PMid: 22591235. https://doi.org/10.1080/03630242.2012.674092

[20] Jongbloed LJ, Schönrock-Adema J, Borleffs JC, et al. Physicians' job satisfaction in their begin, mid and end career stage. Journal of 
Hospital Administration. 2016; 6(1): 1-8. https ://doi.org/10.5 430/jha.v6n1p1

[21] Frank E, McMurray JE, Linzer M, et al. Career satisfaction of US women physicians: results from the Women Physicians' Health Study. Archives of Internal Medicine. 1999; 159(13): 1417-26. PMid: 10399893. https://doi.org/10.1001/archinte.159 .13 .1417

[22] Deshpande SP, Demello J. An empirical investigation of factors influencing career satisfaction of primary care physicians. J Am Board Fam Med. 2010; 23(6): 762-9. PMid: 21057072. https: //doi.org/10.3122/jabfm.2010.06.100075

[23] Holte JH, Kjaer T, Abelsen B, et al. The impact of pecuniary and non-pecuniary incentives for attracting young doctors to rural gen- eral practice. Soc Sci Med. 2015; 128(0): 1-9. PMid: 25569609. https://doi.org/10.1016/j. socscimed.2014.12.022

[24] Hancke K, Igl W, Toth B, et al. Work-life balance of German gynecologists: a web-based survey on satisfaction with work and private life. Arch Gynecol Obstet. 2014; 289(1): 123-9. PMid: 23860692. https://doi.org/10.1007/s00404-013-2949-y

[25] Macartney S, Bishaw S, Fontenot K. Poverty Rates for Selected Detailed Race and Hispanic Groups by State and Place: 2007-2011. U.S. Census Bureau: American Community Survey Briefs. 2013; 2.

[26] Lee D, Fiack KJ, Knapp KM. A profile of solo/two-physician practices. J Health Hum Serv Adm. 2014; 36(3): 297-322. PMid: 24597431. 